\section{P्थ}

Publicado en Internet:

5-noviembre-2015

Lydia Irles Díaz: lydiairlesdiaz@hotmail.com

\title{
Rinorrea de larga evolución: un hallazgo inesperado
}

\author{
L. Irles Díaz ${ }^{a}$, P. Alcaraz Casquillo ${ }^{b}$ B. Gil Peñafiel ${ }^{c}$, M. Mayordomo Serna ${ }^{d}$ \\ aPediatra. CS de Roldán. Murcia. España • bPediatra. CS de Ceutí. Murcia. España • 'Pediatra. \\ CS de Torrepacheco. Murcia. España • PPediatra. CS de Fuente Álamo. Murcia. España.
}

Los cuerpos extraños intranasales son muy frecuentes en niños. La clínica es variada, pudiendo ir desde la ausencia de síntomas hasta perforación del tabique nasal, por lo que realizar el diagnóstico correcto y su extracción es muy importante según determinados cuerpos extraños. El diagnóstico, por tanto, puede hacerse de manera precoz o tardía, según la clínica y la historia del paciente, pero siempre ha de sospecharse ante una clínica persistente.

\section{Long evolution rhinorrhea: an unexpected finding}

\begin{tabular}{|c|c|}
\hline $\begin{array}{r}\text { Key words: } \\
\text { Rhinorrhea } \\
\text { - Nasal foreign body } \\
\text { - Rhinoscopy }\end{array}$ & $\begin{array}{l}\text { Intranasal foreign bodies are very common in children. The symptoms are varied and they can range } \\
\text { from asymptomatic until perforation of the nasal septum, so the correct diagnosis and removal is very } \\
\text { important. The diagnosis can be made early or late, depending on the symptoms and patient's history, } \\
\text { but it always must be suspected when a persistent symptomatology. }\end{array}$ \\
\hline
\end{tabular}

\section{CASO CLÍNICO}

Niña de ocho años que, durante la consulta de un cuadro catarral, refiere que desde hace un año presenta por orificio nasal derecho mucosidad verdosa intermitente, que permite el paso de aire, sin dificultad para la respiración nasal. Dicha mucosidad persiste (aunque con mejoría evidente) tras la curación de los procesos catarrales presentados durante el último año y la desaparición de los mismos durante la época estival. Asocia halitosis importante. No refiere traumatismo previo, ni introducción de cuerpo extraño por fosas nasales, cuadros febriles relevantes ni ronquidos. Ha recibido varios tratamientos antibióticos y lavados nasales.
Se realiza radiografía de Waters (Fig. 1), en donde se observa un edema leve de la mucosa del seno maxilar derecho, compatible con sinusitis derecha leve. En paladar duro existe una imagen lineal radioopaca.

Tras ello es remitida a Otorrinolaringología, donde se le realiza una rinoscopia anterior, encontrando un cuerpo extraño en la fosa nasal derecha (una moneda de 5 céntimos). Tras la retirada del mismo presenta resolución espontánea de la rinorrea en pocos días.

\section{DISCUSIÓN}

La presencia de cuerpos extraños en la vía respiratoria es muy frecuente, suponiendo los intranasales 


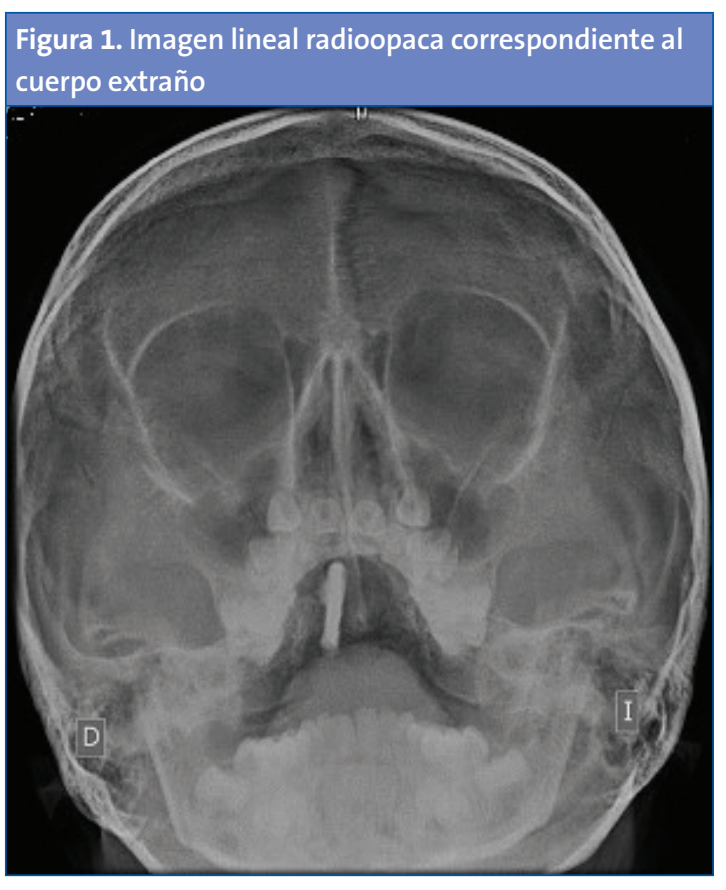

hasta el $66 \%$ de los encontrados en las vías respiratorias. Típicamente se presentan en niños pequeños, preescolares y pacientes con déficit intelectual, y más raramente en los niños mayores y adolescentes ${ }^{1}$. Suelen ubicarse en la fosa nasal derecha, dado que la mayoría de los niños son diestros.

Los cuerpos extraños pueden ser elementos orgánicos o inorgánicos, prácticamente cualquier cosa que permita la entrada por el orificio nasal; muy frecuentes son los papeles, piedras, juguetes pequeños, pendientes, e incluso alimentos como carne, semillas, y trozos de fruta, entre otros. Especial atención merecen como elementos inorgánicos los imanes y las pilas de botón por el riesgo de daño tisular. Las pilas de botón dañan los tejidos por la corriente eléctrica presente en ellas y por la fuga de la carga de baterías; así mismo el polo negativo puede generar iones de hidrógeno y el álcali generado originar daño tisular en horas. Ha sido descrita incluso la perforación del tabique nasal ${ }^{2}$. Los imanes ${ }^{3}$, a diferencia de las pilas de botón, producen el daño de los tejidos de manera más lenta y progresiva, en semanas, y se debe fundamentalmente a la presencia de ellos en cada fosa nasal, siendo atraídos entre sí, causando entonces la compresión del tabique nasal.
Generalmente los cuerpos extraños se ubican bajo el cornete inferior o frente al cornete medio ${ }^{4}$. Los pacientes pueden permanecer asintomáticos, por lo que los padres no sospechan esa posibilidad. En los casos sintomáticos puede haber epistaxis, obstrucción nasal, rinorrea mucopurulenta unilateral, mal olor o halitosis, y respiración bucal ${ }^{5}$. En el caso que exista necrosis tisular puede existir rinorrea mucopurulenta de color negruzca, epistaxis, fiebre y dolor facial simulando una celulitis periorbitaria o una sinusitis ${ }^{6}$. De manera que, ante con un paciente con dichos síntomas, se debe pensar en ello, independientemente de la edad del paciente, del tiempo de evolución y la historia clínica relatada, como sucede en nuestro caso.

En cuanto al diagnóstico, puede realizarse en ocasiones a simple vista, o con ayuda de una luz o un otoscopio. Otras veces es necesaria una radiografía, aunque en muchos casos no será útil, pues los cuerpos extraños en su mayoría son radiotransparentes, aunque serán de gran utilidad en el caso de imanes o pilas de botón. En ocasiones será necesaria una rinoscopia para explorar la cavidad nasal o incluso otras pruebas de imágenes como la tomografía computarizada en el caso de celulitis periorbitaria o sinusitis persistente.

El diagnóstico diferencial va a depender de la clínica presentada. Las patologías más frecuentes a tener en cuenta son las infecciones del tracto respiratorio superior, sinusitis, rinitis alérgica, poliposis nasal e hipertrofia adenoidea.

En cuanto a la extracción del cuerpo extraño, debe realizarse por personal con experiencia, aunque el riesgo de complicaciones en muy bajo. No existen en la literatura científica casos publicados de cuerpos extraños bronquiales derivados de cuerpos extraños nasales. Los imanes y las pilas de botón han de ser retirados de manera urgente para evitar complicaciones. Debe ser valorado por Otorrinolaringología en casos de que el cuerpo extraño no pueda visualizarse ni extraerse por el personal con experiencia. 


\section{CONFLICTO DE INTERESES}

Los autores declaran no presentar conflictos de intereses en relación con la preparación y publicación de este artículo.

\section{BIBLIOGRAFÍA}

1. François M, Hamrioui R, Narcy P. Nasal foreign bodies in children. Eur Arch Otorhinolaryngol. 1998;255:132-4.

2. Guidera AK, Stegehuis HR. Button batteries: the worst case scenario in nasal foreign bodies. N Z Med J. 2010;123:68-73.

3. Yeh B, Roberson JR. Nasal magnetic foreign body: a sticky topic. J Emerg Med. 2012;43:319-21.

4. Heim SW, Maughan KL. Foreign bodies in the ear, nose, and throat. Am Fam Physician. 2007;76:1185-9.
5. Claudet I, Salanne S, Debuisson C. Nasal foreign body in infants. Arch Pediatr. 2009;16:1245-51.

6. Dane S, Smally AJ, Peredy TR. A truly emergent problem: button battery in the nose. Acad Emerg Med. 2000;7:204-6.

7. Qureshi AA, Lowe DA, McKiernan DC. The origin of bronchial foreign bodies: a retrospective study and literature review. Eur Arch Otorhinolaryngol. 2009; 266:1645-8 